\title{
Finding and utilizing opinion leaders: Social networks and the power of relationships
}

\author{
R. van der Merwe \\ eBay, Inc., 2145 Hamilton Avenue, \\ San Jose, CA 95125 \\ G. van Heerden* \\ Division of Industrial Marketing, eCommerce and Supply Chain Management, \\ Luleå University of Technology, Luleå, Sweden \\ vanheerden.gene@gmail.com
}

Received June 2009

\begin{abstract}
Research suggests that consumer choice is sub-optimal: simply we satisfice. Limited data, time and expertise render our rationality 'bounded'. The opinion leader offers a solution to this problem: when faced with a complex choice, we often seek the opinion of an expert. The Web has fueled an unprecedented expansion of this strategy by enabling 'virtual' opinion leaders (see Web sites such as Epinions.com and Amazon.com). However, despite its rise in popularity, opinion leadership has received limited attention in the advertising literature.
\end{abstract}

\begin{abstract}
It is this hiatus that we address and in doing so seek to make two potentially important contributions to the wider research on opinion leadership. First, we link opinion leadership to social network theory and show that, those at individuals who are central to social networks serve as opinion leaders. Second, we challenge the assumption that opinion leadership is monomorphic (topic specific) by showing that domain-specific opinion leadership is strongly related to general opinion leadership.

Our paper is set out as follows. First, we provide overviews of the literatures on opinion leadership and social networks. Second, we outline our methodology and present the results of an empirical study. Finally, we delimit the research, present a framework for identifying opinion leaders, identify key implications, and explore potential avenues for future research.
\end{abstract}

*To whom all correspondence should be addressed.

\section{Introduction}

When consumers choose between different products or services, we know that they will not make their decisions by evaluating every alternative available to them and choosing the best. Herbert Simon's (1982) theory of bounded rationality proposes two reasons for this. First, only limited information is available regarding the range of alternatives and their consequences. Second, people have limited ability to process and evaluate even the information that is available to them. Bounded rationality states that people will therefore make decisions by '[choosing] the first satisfactory alternative to emerge' (Abercrombie, Hill \& Turner, 2000). It seems that in recent times we place even more bounds on our rationality-we have less time available and less money to spend on the evaluation of alternatives. We want to find out all there is to know about a particular product or service as quickly as possible and then make our decisions.

The Internet is a medium that by definition makes it possible to assimilate large amounts of information in a very short time and with virtually no cost to the user. An example of a web site that utilizes how important the quick evaluation of alternatives has become to consumers is Epinions.com [www.epinions.com]. Epinions was founded in May 1999 by executives of leading Internet companies such as Yahoo!, Netscape, and Excite@Home. They created Epinions to help consumers make informed buying decisions by providing them with unbiased reviews and advice that they can trust, and by doing comparison shopping to find the best prices available. They nominate reviewers whose opinions can be trusted by the community, reviewers who influence the buying behavior of consumers significantly. They create opinion leaders.

The study of opinion leadership has escalated recently as its importance for e-business became evident. 'Find out where your users are going on the Web - specifically the opinion leaders who are going to spread the word,' is the advice of Michele Pelino, e-commerce analyst for Yankee Group [www.yankeegroup.com]. In an interview with the Ecommerce Times [www.ecommercetimes.com], Pelino emphasizes that relying on viral marketing to spread the word about new products is not enough. E-commerce companies need to identify who the opinion leaders among customers are, and they need to find out where these leaders 
gather online-that's where their products need to be advertised (Hirsh, 2001). A Roper Starch Worldwide study recently found that 8 percent of the US Internet population are so-called 'e-fluentials', or 'people who are very likely to influence the surfing habits of other users' (Starch, 2000).

While opinion leadership is an important phenomenon, it has actually not received a great deal of attention in the advertising literature of the past decade. While research on opinion leadership is published in the business and marketing literature, it mainly deals with the development and refinement of measurement scales (e.g. Flynn, Goldsmith \& Eastman, 1996); its importance in the social sciences (e.g. Burt, 1999); and its application to various areas related to marketing, such as the health care industry, political science and public relations (e.g. Locock, Dopson, Chambers \& Gabbay, 2001; Howard, , Rogers, HowardPitney \& Flora, 2000; Hoekstra, 1995; Kern-Foxworth, 1992). This paper aims to identify some popular misconceptions about opinion leadership in order to affirm its usefulness beyond sociology and into the world of advertising. We show how social network theory can be used in conjunction with opinion leadership to identify the opinion leaders in a community. We further show how important these opinion leaders can be in the successful marketing of new/existing products or services.

In most consumer behavior texts, opinion leadership is assumed to be largely domain specific - that is, if someone is an opinion leader about a certain product or idea, he or she is somewhat of a specialist, and is not necessarily considered to be an opinion leader in general, concerning all products, services and subjects (Flynn, Goldsmith \& Eastman, 1994; Schiffman \& Kanuk, 1999; Grewal, Mehta \& Kardes, 2000). More recently a counter-position to the above school has involved the identification of the 'market maven', and individual who, in opinion leadership terms is more general. Furthermore, the identification of opinion leaders is usually a very tedious process involving extensive survey research and complex statistical analysis. In this paper we use empirical data from five distinct groups to show that:

- $\quad$ Domain-specific opinion leadership might be strongly related to General opinion leadership. If a person is an opinion leader on a specific subject, it is in fact likely that they will be an opinion leader on all subjects in general.

- $\quad$ The identification of opinion leaders can be simplified through the use of social network theory. Social networks can be used to construct relational networks, and the individuals who are central to these networks can be considered to be the opinion leaders in a specific group/network.

We begin with an overview of the literature on opinion leadership and social networks, including different tools used for measurement. Next we outline the methodology used and present the results of an empirical study designed to identify the opinion leaders in 5 different groups of university students, as well as the nature and strength of relationships within these groups. Finally, some conclusions and managerial implications are drawn, the limitations of the approach identified, and avenues for future research are outlined.

\section{Opinion leadership and its measurement}

The study of opinion leadership has its origins in work by Lazarsfeld, Berelson and Gaudet (1948) in which they discovered that voting decisions were heavily influenced by relatives, friends and co-workers. Rogers (1962) defined opinion leadership as 'the degree to which an individual is able to influence other individuals' opinions or behavior in a preferred way with relative frequency' (Jamrozy, Backman \& Backman, 1996). Burt (1999) provided the business perspective by defining opinion leaders as 'people whose conversations make innovations contagious for the people with whom they speak'. Flynn et al. (1994) applied the concept to marketing as follows: 'as consumers frequently rely upon other people as sources of information, in addition to advertisements and media, opinion leaders exert a disproportionate amount of influence on the decisions of other consumers.'

All these definitions echo and expand on the central idea of opinion leadership as defined by King and Summers (1970), who made the point that 'influence through communication is the hallmark of the opinion leader' (our italics). They distinguished between influence and communication by saying that 'personal influence refers to an effect, while interpersonal communication refers to an exchange of information between individuals', and went on to develop a seven-item, self-reporting scale for opinion leadership that is still widely used today, albeit with some refinements (see Childers, 1986; Flynn et al., 1994).

Opinion leaders can influence their peers in several ways. Chau and Hui (1998) identify three main ways in which opinion leaders 'exert an unequal amount of influence on the decisions of others'. They are '(1) acting as role models who inspire imitation; (2) spreading information via word of mouth; and (3) giving advice and verbal direction for search, purchase, and use'. It seems that consumers often trust the opinions of others more than they do formal marketing sources of information such as advertising (Flynn, et al., 1996).

Opinion leadership is almost always perceived to be domain-specific or monomorphic - in other words, related to a specific area of influence in which the opinion leader is perceived to be knowledgeable. This idea is reinforced in most consumer behavior texts. Schiffman and Kanuk (1999) state that '[the opinion leader] usually offers advice or information about a product or service, such as which of several brands is best, or how a particular product may be used.' Even more recently, Grewal et al. (2000) defined opinion leadership as 'an individual's ability to influence other individuals' attitudes or overt behavior in a desired way in a particular domain' (our italics).

Going back much further to the origins of opinion leadership, we find that Katz (1953) and Lazersfield et al. (1948) assume domain specificity throughout their research and writing on opinion leadership, referring to 'marketing 
leaders', 'fashion leaders' and 'public affairs leaders', among others. They go on to say that 'it is reasonable to suspect that a person who becomes sufficiently interested in any one of these [above-mentioned] areas and/or an active participant in it will be turned to for advice by others. This would suggest that interest in a given arena might be enough to make for opinion leadership'. Cartwright and Zander (1968: 216) picked up on this idea when they developed a model for personal influence. They stated that 'one cannot meaningfully speak of influence or power without specifying, at least implicitly, its 'content'... a foreman may be able to influence a worker's behavior on the job and yet be powerless when it comes to his political activities'.

Consumer behavior literature does provide room for a counter-argument in the form of so-called 'market mavens'. Market mavens are defined as 'individuals who have information about many kinds of products, places to shop, and other facets of markets, and initiate discussions with consumers and respond to requests from consumers for market information' (Feick \& Price, 1987). In essence they are opinion leaders on a wide range of subjects. Williams and Slamal (1995) contend that market mavens are 'likely to influence the buying decisions of a variety of people who seek and/or receive their advice... they are heavy media consumers, so they are easily reachable through advertising media'. Research has shown that market mavens can influence a wide range of buyer behavior (e.g. Walsh \& Mitchell, 2001; Williams \& Slama, 1995; Feick \& Price, 1987). However, there is not a large knowledge base on the subject beyond a few empirical studies and a brief discussion in most consumer behavior textbooks. The domain-specific view of opinion leadership is still widely accepted (see Langeard, Crousillat \& Weisz, 1978; Myers \& Robertson, 1972; Silk, 1966).

As mentioned earlier, the measurement of opinion leadership is usually a very tedious process. Common literature suggests three main ways to identify opinion leaders (Engel, Blackwell \& Miniard, 1987). Respondents can be asked to evaluate their own ability to influence others. This is called the Self-Reporting Method, and the King and Summers (1970) scale is a case in point. Respondents can be asked from whom they get advice and to whom they turn to seek advice on a particular topic or specific setting. We used both this method, called the Sociometric Method, and the Self-Reporting method in this research. Informed individuals can be asked to identify the people they think are opinion leaders. This is called the Key Informant Method.

The applicability of opinion leadership in marketing has always been apparent. The consumer behavior discipline often encourages marketers to use their knowledge of opinion leaders to their advantage. Hawkins, Best, Coney and Carey (1995) suggest four possible courses of action:

- Marketing Research. Opinion leaders relay information to others, and marketing research should therefore focus on samples of individuals likely to be opinion leaders.
- Product Sampling. Sending product samples to opinion leaders can create powerful word-of-mouth marketing.

- Retailing/Personal Selling. Retailers and sales personal can encourage current customers to spread the word about particular products/services.

- Advertising. Advertising should aim both to encourage and to simulate opinion leadership. It can encourage opinion leaders to talk about products, and it can also simulate opinion leadership by using acknowledged opinion leaders to promote products (e.g. Michael Jordan for basketball shoes).

This paper's main concern is with general vs. domainspecific opinion leadership, as well as the contribution that social networks can make to this field of study. We now turn our attention to the social network theories relevant to the topic.

\section{Social network theory and opinion leadership}

The foundations of both opinion leadership and social network theory have often been used together in literature related to the diffusion of innovation. Opinion leadership is seen as a relational model of innovation diffusion, while social networks are seen as a structural model ${ }^{1}$ to describe the phenomenon. Valente (1995) defines social network analysis from this perspective by saying it 'is a technique used to analyze the pattern of interpersonal communication in a social system by determining who talks to whom. Network analysis can be used to understand the flow of personal influence by enabling researchers to define who influences whom in a social system' (our italics). This definition clearly talks about influence through communication, which relates to the Flynn et al. (1994) definition of opinion leadership, as mentioned earlier in this paper. Weimann (1991) also argued for the link between opinion leaders (or 'influentials') and social networks: 'The role of interpersonal relations in the flow of information and influence, as revealed by [previous] studies, caused a growing interest in personal networks and in key positions in these networks' (Weimann, 1991). Interestingly enough, although 'countless studies have attempted to identify the characteristics of opinion leaders in terms of demographic and socio-economic variables, media exposure, social positions, and personally traits' (Weimann, 1991), the relationship between opinion leadership and the structural properties of networks has not been pursued. A natural question to ask is thus: can network analysis be used as an indicator for, or an identifier of, opinion leadership?

One of the main social network tools used in innovation diffusion research is network centrality. Centrality measures

\footnotetext{
${ }^{1}$ Relational models deal with 'patterns of friendship, advice, communication, or support that exists among members of a social system' (Valente, 1995). On the other hand, a network's structural properties have to do with 'the configuration of linkages between people or units' (Nahapiet \& Ghoshal, 1994). It describes 'the overall pattern of connections between actors - that is, who you reach and how you reach them' (Burt, 1992).
} 
aim to identify prominent actors in a network by finding those actors that are extensively involved in relationships with other actors, and therefore more visible to others. In general then, 'a central actor [is an actor that is] involved in many ties' (Wasserman \& Faust, 1994). Once again, Valente (1995) makes the connection with opinion leadership: 'In essence, the opinion leader model is a simplified model of the role of centrality in the diffusion of innovations. In the language of network analysis, opinion leaders, measured as those receiving the most nominations, have a relatively high [centrality].' Although this link has therefore been established in theory, empirical research to support this assumption has not been forthcoming. One of the aims of this paper is to fill this gap in the research. It is important to note that our focus is primarily on opinion leadership, and the reference to innovation diffusion theory is used purely as a means to that end.

Network centrality can be measured in several ways. Degree centrality measures the proportion of actors that are adjacent to a particular actor. This can be divided further into indegree centrality (the number of nominations received by a particular actor from other actors) and out-degree centrality (the number of nominations sent by a particular actor to other actors). Closeness centrality measures how close an actor is to all the other actors in the network, while betweenness centrality identifies actors that are between many actors in their linkages with each other (Wasserman \& Faust, 1994). All these measures are significant in their own right, but we felt that a stronger, overall measure of centrality was needed. We tested correlations with opinion leadership using several measures, including in-degree, outdegree, in-closeness, out-closeness and betweenness centrality. Eventually we opted for the Power measure found in Burt's (1991) social network analysis software called STRUCTURE. Along with simple degree centrality measures, STRUCTURE also computes a sophisticated centrality measure that Burt calls Power, which measures 'the extent [to which an actor] is the object of exclusive relations from people whose interaction is highly valued' (Burt, 1991). This measure has its origins in groundbreaking work done by Katz (1953), Hubbell (1965) and Bonacich (1972), and relies on the assumption that simply counting the number of nominations an actor receives is not enough, because 'power comes from exclusive relations with powerful players' (Burt, 1992). This is therefore the measure used throughout the study to compute prominence and centrality in a network.

\section{Hypotheses and methodology}

Based on the literature and the nature of this study we formulated the following three hypotheses:

$\mathrm{H}_{1}$ : A high correlation exists between domain-specific opinion leadership and non domain-specific opinion leadership.

$\mathrm{H}_{2}$ : A high correlation exists between self-reported opinion leadership and opinion leadership as reported by others.

$\mathrm{H}_{3}$ : A high correlation exists between centrality in a relational network and opinion leadership.
In order to perform this research, we needed to collect data relating both to opinion leadership and to network properties. The data was collected through survey questionnaires distributed to five different groups of college students, each consisting of approximately 25 undergraduate students. These students had spent a full semester in the same group, meeting on a regular basis for classes and to discuss group assignments as well as individual assignments. Within each class, a survey questionnaire was distributed to every student to collect data related to three areas:

- $\quad$ A self-reporting measure of opinion leadership.

- A measure of opinion leadership as reported by their classmates.

- $\quad$ Sociometric friendship data to measure the structural properties of the networks.

The groups were analyzed separately to demonstrate the consistency of the results. By using five different groups and analysing them separately we are able to show that the results will be dependable when performed multiple times. Obviously, analysing the group as a whole would make the results less generalizable.

An example of the questionnaire used for group 4 is attached. For the self-reporting measure of opinion leadership, we used Flynn et al., (1994) 6-item scale, as they adjusted it from the original 7-item King and Summers (1970) scale. This 6-item scale deals with both domainspecific leadership (Question 1 - 5) as well as non domainspecific opinion leadership (Question 6), using a 5-point Likert scale. To measure domain-specific opinion leadership, students were asked to comment on the gaming consoles product category, i.e. products such as Microsoft's Xbox and Sony's Playstation 2. Students had spent a considerable amount of time working with this topic in group and class assignments, and it is therefore reasonable to assume that they would all be knowledgeable in this particular area.

To measure opinion leadership as reported by their classmates, we presented each student with a list of all their classmates, and asked them to indicate whom they would generally ask for advice on the particular topic (domainspecific). To collect sociometric friendship data within each group, we again presented students with a list of all their classmates, and asked them to indicate the nature of their relationship with each person in the class (non domainspecific). Students could choose from five relationship categories, as used in the work of Krackhardt and Stern (1988): 'trust as a friend', 'know well', 'acquaintance', 'associate name with face', and 'do not know'.

It is important to note why we chose to use relational friendship data to construct the social networks and find the structural properties in the network. These relational factors describe the kind of personal relationships people have developed with each other through a history of interactions (Granovetter, 1992). Nahapiet and Ghoshal (1994) go on to say that 'this concept focuses on the particular relations 
people have, such as respect and friendship, that influence their behavior' (our italics). Again, the basic premise of opinion leadership is apparent. Friendships are therefore clearly the best measure of structural network properties when it comes to opinion leadership. Nahapiet \& Ghoshal (1994) conclude, 'two actors may occupy equivalent positions in similar network configurations, but if their personal and emotional attachments to other network members differ, their actions also are likely to differ in important respects.' This approach brings an essential relational component to the calculation of structural network properties.

A total of 123 questionnaires were distributed in the five groups. The data was then analyzed using SPSS 10.0 for Windows and Burt's STRUCTURE software (available from

[http://gsbwww.uchicago.edu/fac/ronald.burt/teaching]).

\section{Results and discussion}

The reliability of the six-item King and Summers opinion leadership scale (Q1 - Q6) was established using Cronbach's alpha as a measure of internal consistency. The alpha for the scale was .85, which adequately meets the standards required for such research (e.g. Nunnally, 1978). Factor analysis of the items in the scale, using the eigenvalues $>1$ criterion, with VARIMAX rotation, revealed the presence of only one factor, which means that items 1 through 6 (Q1 to Q6) could simply be summed to produce an overall composite measure of opinion leadership. A factor analysis of items 1 through 5 (Q1 to Q5) revealed the presence of only one factor as well, which meant that these items could also be summed as an overall measure of domain-specific opinion leadership. We then proceeded to test the hypotheses in three stages:

a) The correlation between domain-specific opinion leadership (items Q1 to Q5) and non domain-specific opinion leadership (item Q6).

b) The correlation between self-reported opinion leadership and opinion leadership as perceived by others.

c) The correlation between opinion leadership and network centrality (power measure).

A linear regression analysis with Q6 as the dependant variable and Q1-Q5 as the independent variable revealed an $\mathrm{R}^{2}$ of 0.353 significant at $\mathrm{p}<0.01$ (see Table 1 ). This relationship can also be seen as evidence of convergent validity, as the items that make up the opinion leadership scale correlate significantly with what make be seen as $n$ independent overall measure. Obviously this is not surprising given that a factor analysis of the six items in any case revealed only one factor, which means that these items are all significantly correlated. We therefore conclude that domain-specific opinion leadership as measured by Q1-Q5 is positively related to non domain-specific opinion leadership (Q6). Individuals who perceive themselves to be opinion leaders in a specific domain believe that they are opinion leaders in general as well. We therefore accept $\mathrm{H}_{1}$.
As mentioned earlier, the consumer behavior literature refers to these people as market mavens, people who '[possess] a large amount of information about a variety of products, categories, retails concepts, and markets... they have high levels of brand awareness and like to share their information with others' (Blackwell, Miniard \& Engel, 2001).

Table 1: Linear regression: Domain-specific vs. Non Domain-specific opinion leadership

\begin{tabular}{c|c|c|c|c}
\hline \multicolumn{5}{c}{ Model summary } \\
\hline Model & R & R Square & $\begin{array}{c}\text { Adjusted } \\
\text { R square }\end{array}$ & $\begin{array}{c}\text { Std. error } \\
\text { of the } \\
\text { estimate }\end{array}$ \\
\hline 1 &, $594^{\mathrm{a}}$ &, 353 &, 325 &, 7783 \\
\hline${ }^{\mathrm{a}}$ Predictors:
\end{tabular}

${ }^{\mathrm{a}}$ Predictors: (Constant), Q5, Q1, Q3, Q4, Q2

\begin{tabular}{c|c|c|c|c|c}
\hline \multicolumn{7}{c}{ ANOVA $^{\mathbf{b}}$} & Sig. \\
\hline Model & $\begin{array}{c}\text { Sum of } \\
\text { squares }\end{array}$ & df & $\begin{array}{c}\text { Mean } \\
\text { square }\end{array}$ & F & \\
\hline 1 & & & & & \\
$\begin{array}{c}\text { Regression } \\
\text { Residual } \\
\text { Total }\end{array}$ & 38,606 & 5 & 7,721 & 12,746 &, $000^{\mathrm{a}}$ \\
\hline
\end{tabular}

${ }^{\text {a }}$ Predictors: (Constant), Q5, Q1, Q3, Q4, Q2

${ }^{\mathrm{b}}$ Dependent variable: Q6

The second task was to measure the correlation between self-reported opinion leadership and opinion leadership as reported by others. Self-reported opinion leadership was measured by summing the values of Q1 to Q6 provided by each respondent to calculate a total measure of self reported opinion leadership. A measure for opinion leadership as reported by others was calculated by weighting the nominations each person received from their classmates. When asked whether or not they would ask each of their classmates for advice on gaming consoles, the answers were weighted as follows: 'Never' $=0$ nominations; 'Sometimes'=1 nomination; 'Often'=2 nominations and 'Always'=3 nominations. The number of nominations was then summed to calculate a total measure of opinion leadership as perceived by others. A correlation analysis was performed on these two measures-the results are shown in Table 2.

Table 2 - Correlation between self-reported opinion leadership and opinion leadership as reported by others

\begin{tabular}{l|c}
\hline Group number & Correlation \\
\hline Group 1 (24 students) &, $584^{* *}$ \\
\hline Group 2 (21 students) &, $650^{* *}$ \\
\hline Group 3 (29 students) &, $402^{*}$ \\
\hline Group 4 (27 students) &, $604^{* *}$ \\
\hline Group 5 (22 students) &, $665^{* *}$ \\
\hline$* *$ significant at the 0,01 level (2-tailed) & \\
$*$ significant at the 0,05 level (2-tailed) &
\end{tabular}

From Table 2 it is apparent that there is a strong correlation between individuals' perceptions of their opinion leadership status, and what others seem to think of them as opinion leaders. We can therefore generalize that opinion leadership is defined and identified similarly by different individuals in 
different situations. This can also be seen as an indication of the external validity of the King and Summers scale, and we accept $\mathrm{H}_{2}$. This finding is important because it shows that even though people may not even be aware of the term 'opinion leader', they are generally aware of the basic premise behind the theory - that some people have a much stronger ability to influence thinking than others. It also demonstrates that not only do people agree on who the opinion leaders are, the opinion leaders themselves are aware of the fact as well.

The third task was to test the correlation between opinion leadership and network centrality. Each network was analyzed using STRUCTURE to find the Power centrality measure, as described in the previous section. In order to do this, a sociogram (matrix of links between different actors) was constructed for each group as well as visual map of the network created with software called Cyram Netminer 1.1.5. Links between classmates were valued to distinguish between weak links and strong links between them. The value of the links indicates the strength of the friendship between classmates also used a five-point scale anchored on, 'Do not know' $=0$; 'Associate name with face' $=1$; 'Acquaintance'=2; 'Know well' $=3$ and 'Trust as a friend' $=4$. A ' 0 ' link is therefore indicative of no friendship, and a ' 4 ' indicates a strong friendship. It is important to note that this is a directional network-Person A may nominate Person B as a friend, but the nomination may not be returned. For example, if A nominates B as a 'Know well' relationship, and $\mathrm{B}$ nominates $\mathrm{A}$ as an 'Associate name with face' relationship, $A \rightarrow B$ will have a valued score of 3 , while $\mathrm{B} \rightarrow \mathrm{A}$ will have a valued score of 1 . This matrix of relationships (sociogram) was used as the input to STRUCTURE.

The Power measure of centrality was then correlated with the total self-reported opinion leadership measure (OL self) and the total measure for opinion leadership as perceived by others (OL other). The results are shown in Table 3.

Table 3 - Correlation between centrality (power) and opinion leadership

\begin{tabular}{l|l|l}
\hline $\begin{array}{l}\text { Power of Group x Correlated With } \\
\rightarrow\end{array}$ & OL (self) & OL (other) \\
\hline Group 1 (24 students) &, 242 &, $520^{* *}$ \\
\hline Group 2 (21 students) &, $662^{* *}$ &, $698^{* *}$ \\
\hline Group 3 (29 students) &, 150 &, $684^{* *}$ \\
\hline Group 4 (27 students) &, $535^{* *}$ &, $571^{* *}$ \\
\hline Group 5 (22 students) &, $522^{*}$ &, $691^{* *}$ \\
\hline ** significant at the 0,01 level (2-tailed) \\
$*$ significant at the 0,05 level (2-tailed)
\end{tabular}

From Table 3, it is apparent that although the correlation between centrality and self-reported opinion leadership is not always significant, the correlation with opinion leadership as perceived by others is always significant at the 0.01 level. We therefore accept $\mathrm{H}_{3}$, which leads us to the important conclusion that opinion leadership as perceived by others is strongly related to a person's structural position in a network. We now consider the managerial and research implications of these findings. While it might be noted that the correlation between centrality and self-reported opinion leadership is not always significant, this is not the focus of the paper. Our emphasis and hypothesis is on the correlation between centrality and opinion leadership as perceived by others, which, it will be noted as significant across the board.

\section{Managerial implications}

The findings of this study have significant implications for advertising. Presently, when marketers want to exploit opinion leadership in their marketing campaigns, it can be a very tedious process. Because of the assumption that opinion leadership is domain-specific and therefore related to specific products, marketers may have to go through long periods of market research to identify opinion leaders in the product category they want to focus on. For example a pharmaceutical firm may find that rather than bombarding a whole community of medical practitioners with promotional material, advertising, and very short visits by sales representatives, resources may be better utilized by concentrating them on a few identified opinion leaders, who will then influence their peers on the firm's behalf. However, our study shows that domain-specific opinion leadership is related to opinion leadership in general. This means that marketers do not have to look for opinion leaders in a specific category, all they have to do is look for leaders and people of influence within a certain community, and these people are very likely to be the opinion leaders in that community. As the need arises, marketers can then target these people on a regular basis to promote their products.

However, finding these opinion leaders can be difficult task as it usually involves extensive survey research. Social networks provide a solution to this problem. Our research suggests that a person's structural position in a network is a good indication of opinion leadership. This is especially true in terms of other peoples' perceptions; although it is also true, to a lesser degree, in terms of a person's own perception of his opinion leadership. This means that marketers might not have to spend a lot of time and effort to find the domain-specific opinion leaders they are looking for. They don't even have to find general opinion leaders, or market mavens. All they need to do is look at the structure of the social networks of a certain community. Through social network theory and its measures it is then possible to identify who the central actors of the network are. These central actors will tend to be the opinion leaders in that community, and by implication marketers can target these leaders for their domain-specific purposes. The fact that the structural centrality measures of a network are so strongly related to whom people perceive to be opinion leaders therefore provides a very important tool to identify opinion leaders. A general framework for the identification of opinion leaders using this approach is shown in Figure 1. 


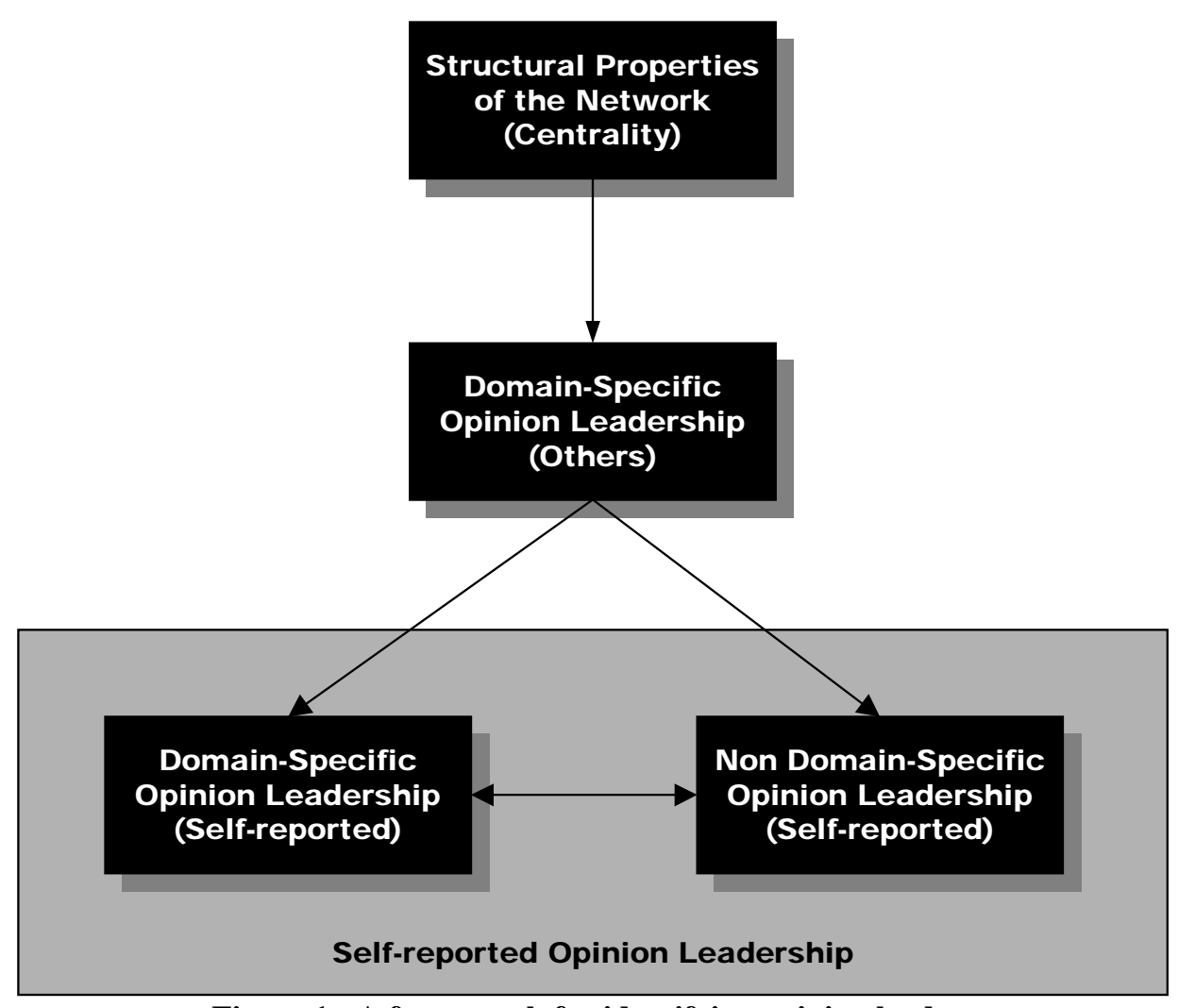

Figure 1 - A framework for identifying opinion leaders

The framework suggests a systematic way to identify opinion leaders. Researchers start by collecting sociometric data about the group/community they are interested in. The data can be collected using the roster method as we have done (providing a list of all the people in the group), but for larger groups the free recall method can also be used (presenting respondents with a blank page and asking them to identify the relationships between them and the other members of the group) (Wasserman \& Faust, 1994). It is preferable to make use of valued links, as it provides a measure of the strength of the relationship. The use of STRUCTURE or similar network analysis software programs can then identify the actors that are most central to the network. These people will generally be perceived to be the opinion leaders in a specific domain and by implication opinion leaders in general. These are the people that should be targeted by marketers in the various ways described earlier. Numerous studies have shown that opinion leadership is in many markets the single strongest factor causing a purchasing decision, making them a vital segment of the target market (e.g. Bansal \& Voyer, 2000; Kohli, 1989; Webster, 1988).

The approach has numerous advantages for advertisers, including efficient use of resources and more specific targeting of marketing efforts. A company possessing a social network of the market(s) it serves has an enduring blueprint that can be used over a relatively long period of time and for a variety of marketing initiatives. Obviously this network will have to be updated periodically as central actors move, retire, die or lose their influence, but this is arguably not a major drawback. A far more important caveat is that marketers must understand that just as networks can spread positive information and opinions, they can also be negative if the situation merits it. Just as opinion leaders can communicate the positive features, benefits and advantages of a marketer's products and services, they can also convey the negatives to their followers. This drawback will be augmented by the fact that this communication will probably be more intense and more rapid. However, the one factor that would still be working to the advantage of the owner of an identified network is that much more specific and targeted attempts can be made to alleviate the consequences of negative communication. They would still be better off than marketers who did not possess identified documented networks.

\section{Conclusions, limitations and areas for future research}

Marketers see the process of identifying opinion leaders as tedious and time-consuming, and although they recognize the many advantages of using opinion leadership in their discipline, the process often seems too clumsy and imprecise to bother researching the possibilities. This paper has made two contributions to the current body of knowledge:

- It has shown that general opinion leadership (non domain-specific) is indeed a good indicator of domain-specific opinion leadership. It is therefore much easier to identify opinion leaders because the added complexity provided by different domains and product categories might be less important than at first thought.

- It has shown that social network analysis can be used to identify opinion leaders. It is relatively easy to identify friendship networks within a small group/community using survey research. Network data 
can be analyzed to identify central actors in the network who also, according to our research, tend to be opinion leaders within that group/community. This method provides a refreshing alternative to the tiresome job of finding opinion leaders through the more traditional tools of questionnaire survey research. What makes this solution potentially even more significant is that the social networks that are constructed can also be used in many different marketing areas. This includes the identification of entrepreneurial opportunities called 'structural holes' (Burt, 1992) and the modification of networks to improve communication flow between organizations and different stakeholders (Cross, Borgatti \& Parker, 2002). It is this possibility of multiple applications that makes the use of social networks so attractive.

There are obviously limitations to the research described here in its current stage. First, we studied domain-specific opinion leadership in only one domain: gaming consoles. It is necessary to study the link between domain-specific and non-domain specific in more domains to establish a stronger foundation from which to make conclusions about their correlation. Second, although we used 6 different measures of centrality, there are still other constructs that can be used to measure prominence and centrality in networks (Wasserman \& Faust, 1994). It would be necessary to study the correlation between these measures and opinion leadership to establish whether or not there is a stronger indication of opinion leadership than the Power measure used in this research. Further, this study was quite small (5 groups with approximately 25 members per group) and it needs to be expanded to more groups with more members to each group. It would also be useful to use business people and more experienced consumers in the study instead of university students. Students are sometimes considered to be less reliable sources of information than the more mature consumer groups.

These issues and others presented earlier open up many other avenues for future research. Some are studying bigger networks or entire communities to establish whether or not our findings can be generalized to include much larger networks; Studying the network properties more closely to establish more areas in which the various analysis techniques can be applied to marketing; Studying different centrality measures to establish an even more reliable framework for the identification of opinion leadership using social networks and lastly continuing research on the interface between opinion leadership and marketing in the light of these findings, in order to find more business applications than the ones commonly used today.

We hope this paper may serve as a catalyst to future research into the role of opinion leadership in marketing. Social network analysis is a powerful tool, and combining it with opinion leadership knowledge may provide exciting new applications in marketing.

\section{References}

Abercrombie, N. Hill, N.S. \& Turner, B.S. 2000. The penguin dictionary of sociology. $4^{\text {th }}$ Edition. London: Penguin Books.
Bansal, H.S. \& Voyer, P.A. 2000. 'Word-of-mouth processes within a services purchase decision context', Journal of Service Research, 3(2):166-177.

Blackwell, R.D., Miniard, P.W. \& Engel, J.F. 2001. Consumer behavior. $9^{\text {th }}$ Edition. Orlando: Harcourt College Publishers.

Bonacich, P. 1972. 'Factoring and weighting approaches to status scores and clique identification', Journal of Mathematical Sociology, 2: 113-120.

Burt, R.S. 1991. STRUCTURE reference manual, Version 4.2. New York: Columbia University.

Burt, R.S. 1992. Structural holes: The social structure of competition. Cambridge: Harvard University Press.

Burt, R.S. 1999. 'The social capital of opinion leaders', Annals of the American Academy of Political and Social Science, November: 1-22.

Cartwright, D. \& Zander, A. 1968. Group dynamics Research and theory. $3^{\text {rd }}$ Edition. Tavistock Publications Limited.

Chau, P.K. \& Hui, K.L. 1998. 'Identifying early adopters of new IT products: A case for Windows 95', Information \& Management, 33:225-230.

Childers, T.L. 1986. 'Assessment of the psychometric properties of an opinion leadership scale', Journal of Marketing Research, 23 (May):184-188.

Cross, R., Borgatti, S.P. \& Parker, A. 2002. 'Making invisible work visible: Using social network analysis to support strategic collaboration', California Management Review, 44(2): 25-46.

Engel, J.F., Blackwell R.D. \& Miniard, P.W. 1987. Consumer behavior. $5^{\text {th }}$ Edition. Chicago: The Dryden Press.

Feick, L.F. \& Price, L.L. 1987. 'The market maven: A diffuser of marketplace information', Journal of Marketing, 51(January):83-97.

Flynn, L.R., Goldsmith, R.E. \& Eastman, J.K. 1994. 'The King and Summers Opinion Leadership Scale: Revision and refinement', Journal of Business Research, 31: 55-64.

Flynn, L.R., Goldsmith, R.E. \& Eastman, J.K. 1996. 'Opinion leaders and opinion seekers: Two new measurement scales', Journal of the Academy of Marketing Science, 24(2): 137-147.

Granovetter, M. 1992. 'Problems of explanation in economic sociology’. In Networks and organizations: structure, form, and action, Nohria, N. and Eccles, R.G. (Eds.). Boston, MA: Harvard Business School Press, 25-56.

Grewal, R., Mehta, R. \& Kardes, F.R. 2000. 'The role of the social-identity function of attitudes in consumer 
innovativeness and opinion leadership', Journal of Economic Psychology, 21: 233-252.

Hawkins, D.I., Best, R.J., Coney, K.A. \& Carey, K.A. 1995. Consumer behavior: Implications for marketing strategy. $6^{\text {th }}$ Edition. New York: McGraw-Hill/Irwin.

Hirsh, L. 2001. 'Tell a friend: Viral marketing packs clout online', E-commerce Times, October 31. http://www.ecommercetimes.com/story/14295 html?wlc=12 51910901. Accessed July 8, 2003.

Hoekstra, V.J. 1995. 'The Supreme Court and opinion change: An experimental study of the court's ability to change opinion', American Politics Quarterly, 23:109-129.

Howard, K.A., Rogers, T., Howard-Pitney, B. \& Flora, J.A. 2000. 'Opinion leaders' support for tobacco control policies and participation in tobacco control activities', American Journal of Public Health, 90(8):1282-1287.

Hubbell, C.H. 1965. 'An input-output approach to clique detection’, Sociometry, 28: 377-399.

Jamrozy, U., Backman, S.J. \& Backman, K.F. 1996. 'Involvement and opinion leadership in tourism', Annals of Tourism Research, 23(4): 908-924.

Katz, L. 1953. 'A new status index derived from sociometric analysis’, Psychometrika, 18: 39-43.

Kern-Foxworth, M. 1992. 'Martin Luther King Jr.: Minister, civil rights activist, and public opinion leader', Public Relations Review, 18(3):287-297.

King, C.W. \& Summers, J.O. 1970. 'Overlap of opinion across consumer product categories', Journal of Marketing Research, 7 (February): 43-50.

Kohli, A. 1989. 'Determinants of influence in organizational buying: A contingency approach', Journal of Marketing, 53(July):50-65.

Krackhardt, D. \& Stern, R.N. 1988. 'Informal networks and organizational crises: An experimental simulation', Social Psychology Quarterly, 51(2): 123-140.

Kvicala, J. 2002. 'Home Depot CEO Bob Nardelli reaffirms goal of becoming $\$ 100$ Billion company by 2007 despite 'unprecedented, uncharted, turbulent times', Terry College of Business - News, August 16. URL: http://www.terry.uga.edu/news/releases/2002/ttt nardelli ht ml. Accessed July 8, 2003.

Langeard, E., Crousillat, M. \& Weisz, R. 1978. 'Exposure to cultural activities and opinion leadership', Advances in Consumer Research, 5:606-610.

Lazarsfield, P., Berelson,B. \& Gaudet, H. 1948. The people's choice. New York: Columbia University Press.

Locock, L., Dopson, S., Chambers, D. \& Gabbay, J. 2001. 'Understanding the role of opinion leaders in improving clinical effectiveness', Social Science \& Medicine, 53(6):745-757.

Myers, J.H. \& Robertson, T.S. 1972. 'Dimensions of opinion leadership', Journal of Marketing Research, 9(February):41-46.

Nahapiet, J. \& Ghoshal, S. 1994. 'Social capital, intellectual capital, and the organizational advantage', Academy of Management Review, 23(2): 242-267.

Nunnally, J.C. 1978. Psychometric theory. New York: McGraw-Hill.

Rogers, E. 1962. Diffusion of innovations. New York: Free Press.

Schiffman, L.G. \& Kanuk, L.L. 1999. Consumer behavior. $7^{\text {th }}$ Edition. Prentice Hall.

Sellers, P. 1996. 'Can Home Depot fix its sagging stock?', Fortune, 133(4), March 4 [Online] URL:: http://money.cnn.com/magazines/fortune/fortune archive/19 96/03/04/210046/index.htm

Silk, A.J. 1966. 'Overlap among self-designated opinion leaders: A study of selected dental products and services', Journal of Marketing Research, 3(August):255-259.

Simon, H.A. 1982. Models of bounded rationality, Volume 2. Cambridge: MIT Press.

Starch, R. 2000. 'Online opinion leaders are highly influential', Nua Internet Surveys, June 19. URL:http://www.nua.ie/surveys/?f=VS\&art id=905355852 \&rel=true. Accessed July 14, 2003.

Valente, T.W. 1995. Network models of the diffusion of innovations. Cresskill: Hampton Press.

Walsh, G. \& Mitchell, V.W. 2001. 'German market mavens' decision making styles', Journal of Euro-Marketing, 10(4):83-108.

Wasserman, S. \& Faust, K. 1994. Social network analysis methods and applications. Cambridge: Cambridge University Press.

Webster, C. 1988. 'The importance consumers place on professional services', Journal of Services Marketing, 2(1):59-70.

Weimann, G. 1991. 'The influentials: Back to the concept of opinion leaders?', Public Opinion Quarterly, 55: 267-279.

Williams, T.G. \& Slama, M.E. 1995. 'Market mavens' purchase decision evaluative criteria: Implications for brand and store promotion efforts', Journal of Consumer Marketing, 12(3):4-21. 


\section{Name:}

Thank you for taking the time to fill out this questionnaire.

Please answer the following questions regarding you and your classmates in this tutorial group.

Circle the number that best describes your answer.

1. In general, do you talk to your classmates about gaming consoles?

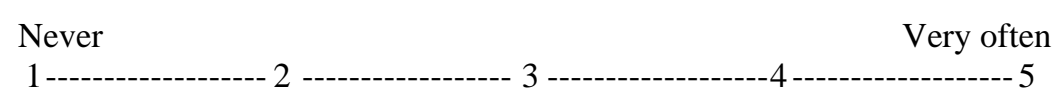

2. When you talk to your classmates about gaming consoles, do you:

Give very little information

1------------------- 2
Give a great deal

of information

3. During the past six months, how many people have you told about gaming consoles?

Told no one
1 -

4. Compared with your classmates, how likely are you to be asked about information on gaming consoles?

Not at all likely $\quad$ Very likely to to be asked

1------------------- 2 $-3$

to be asked 5

5. In discussions of gaming consoles, which of the following happens most often:

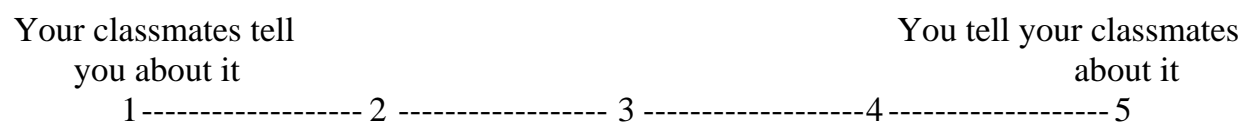

6. Overall in all of your discussions with classmates are you:

Not used as a

source of information

1
Often used as a source of information 
7. Which of the following people would you ask for advice if you needed information on gaming consoles? Place a check in the space that best describes your answer. ${ }^{2}$

\begin{tabular}{|c|c|c|c|c|}
\hline & Never & Sometimes & Often & Always \\
\hline \multicolumn{5}{|l|}{ Ai Geh } \\
\hline \multicolumn{5}{|c|}{ Andrew } \\
\hline \multicolumn{5}{|l|}{ Anita } \\
\hline \multicolumn{5}{|l|}{ Craig } \\
\hline \multicolumn{5}{|l|}{ Eleanor } \\
\hline \multicolumn{5}{|c|}{ Elizabeth } \\
\hline \multicolumn{5}{|l|}{ Fenny } \\
\hline \multicolumn{5}{|c|}{ Huang Ing } \\
\hline \multicolumn{5}{|l|}{ Ivan } \\
\hline \multicolumn{5}{|l|}{ Jennifer } \\
\hline \multicolumn{5}{|l|}{ Jenny } \\
\hline \multicolumn{5}{|l|}{ Jessie } \\
\hline \multicolumn{5}{|l|}{ Kinna } \\
\hline \multicolumn{5}{|l|}{ Martin } \\
\hline \multicolumn{5}{|l|}{ Mei } \\
\hline \multicolumn{5}{|l|}{ Melinda } \\
\hline \multicolumn{5}{|c|}{ Merina } \\
\hline \multicolumn{5}{|c|}{ Moe Moe Ma } \\
\hline \multicolumn{5}{|l|}{ Peter } \\
\hline \multicolumn{5}{|l|}{ Robert } \\
\hline \multicolumn{5}{|c|}{ Shammara } \\
\hline \multicolumn{5}{|l|}{ Tanya } \\
\hline \multicolumn{5}{|c|}{ Thomas } \\
\hline \multicolumn{5}{|l|}{ Tim } \\
\hline \multicolumn{5}{|l|}{ Unggul } \\
\hline \multicolumn{5}{|l|}{ Viet } \\
\hline Zerry & & & & \\
\hline
\end{tabular}

8. Please place a check in the space that best describes your relationship with each person in your class:

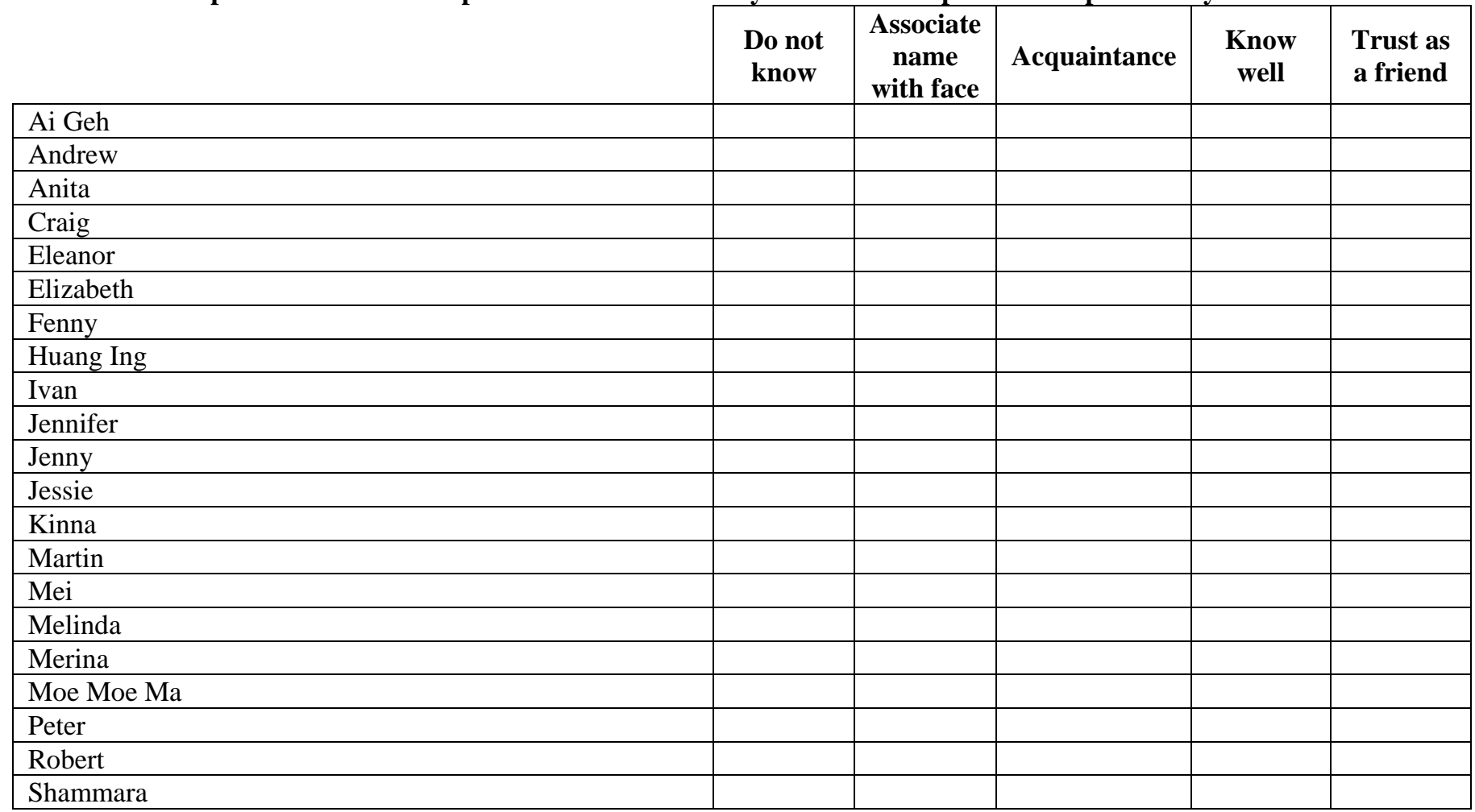

\footnotetext{
${ }^{2}$ In the actual questionnaire used, the students were also identified by their surnames. In order to protect their privacy however, we have chosen to omit these in the table(s).
} 


\begin{tabular}{|l|l|l|l|l|}
\hline Tanya & & & & \\
\hline Thomas & & & & \\
\hline Tim & & & & \\
\hline Unggul & & & & \\
\hline Viet & & & & \\
\hline Zerry & & & & \\
\hline
\end{tabular}

